\title{
OS SALÁRIOS DOS PROFESSORES E A SEGMENTAÇÃO DOS POSTOS DE TRABALHO NO BRASIL
}

TEACHERS' SALARIES AND SEGMENTATION OF JOBS IN BRAZIL

\author{
Vanessa Fortunato de Paiva ${ }^{1}$ \\ Solange de Cassia Inforzato de Souza ${ }^{2}$ \\ Magno Rogério Gomes ${ }^{3}$
}

\section{RESUMO}

Este trabalho tem como objetivo analisar os determinantes salariais dos professores com formação superior no Brasil e os efeitos que os níveis de ensino nos quais atuam exercem sobre os salários. Com base nos microdados da Pesquisa Nacional por Amostra de Domicílios Contínua (PNAD-C) de 2018, estimam-se as equações salariais e mensuram-se as fontes das desigualdades salariais entre os docentes. A constatação é de que os salários dos professores estão relacionados positivamente aos seus atributos produtivos, como também ao nível de atuação profissional, no ensino fundamental, médio e superior. Entretanto, fatores como ser mulher e não branco reduzem os salários dos docentes, mais intensamente em níveis de atuação mais elevados. Apesar de importantes, as dotações produtivas explicam menos as desigualdades salariais dos professores, sendo a estrutura própria das carreiras o fator preponderante, o que afirma a existência de segmentação dos postos de trabalho na profissão docente no Brasil.

Palavras-chave: diferenças salariais; professores; níveis de ensino; segmentação ocupacional.

\begin{abstract}
This paper aims to analyze the salary determinants of teachers with higher education in Brazil and the effects of the levels of education in which they work on salaries. Based on data from the 2018 National Continuous Household Sample Survey (PNAD-C), salary equations are estimated and sources of teachers' pay inequalities are measured. The findings are that teachers' salaries are positively related to their productive attributes, as well as to the acting level, in elementary, secondary and higher education. Being female and not white reduces teachers' salaries, most intensely for higher levels of education. Although important, the productive endowments explain less the salary inequalities of teachers, being the own structure of the careers the predominant factor, affirming the existence of segmentation of the jobs in the teaching profession in Brazil.
\end{abstract}

Keywords: salary differences; teachers; levels of education; occupational segmentation.

JEL: J24, J31, J42

1 Mestre em Economia Regional pela Universidade Estadual de Londrina, Paraná.

2 Doutora em Educação: história, política, sociedade pela Pontifícia Universidade Católica de São Paulo, São Paulo. Mestre em Economia pela Pontifícia Universidade Católica de São Paulo, São Paulo.

3 Doutorando em Teoria Econômica pela Universidade Estadual de Maringá, Paraná. Mestre em Economia Regional pela Universidade Estadual de Londrina, Paraná. 


\section{INTRODUÇÃO}

A relação positiva entre a escolaridade e o rendimento dos trabalhadores é um dos padrões empíricos mais bem estabelecidos na literatura econômica nacional e internacional, assim como também o é a relevância do sistema educacional e do professor para o desenvolvimento cognitivo e social do indivíduo. Todavia, o enfrentamento das dificuldades no mercado de trabalho docente brasileiro devido aos baixos salários, a intensificação da jornada de trabalho e a desvalorização social são comumente tratadas na literatura como fatores causais da baixa atração de profissionais para a carreira docente.

Por outro lado, há uma ampla produção normativa-incluindo leis, resoluções, pareceres e outros - que regulamenta a profissão docente no Brasil. Ancorada pelo Plano Nacional de Educação (PNE) para 2014-2024, a valorização dos profissionais do magistério representa um grande desafio no Brasil, pois passa pela qualidade da formação docente, pela estruturação de sua carreira, por sua remuneração e pelas condições de trabalho (BRASIL, 2015). Entre as 20 metas dispostas no PNE, duas despontam: uma se refere à equiparação do rendimento médio dos professores da educação básica da rede pública ao dos demais profissionais com escolaridade equivalente, e outra à necessidade do plano de carreira e remuneração, com o cumprimento da Lei n. ${ }^{\circ}$ 11.738/2008, que estabelece o Piso Salarial Profissional Nacional (BRASIL, 2008).

Ainda assim, em 2018 os dados do Relatório do 2. ${ }^{\circ}$ Ciclo de Monitoramento das Metas do PNE confirmaram a situação desfavorável dos salários dos professores da educação básica em relação aos demais profissionais de escolaridade equivalente (BRASIL, 2018). Muito embora a ênfase encontrada na literatura empírica esteja nos docentes da educação básica, pesquisadores como Alves e Pinto (2011), Barbosa (2011), Britto e Waltenberg (2012) e Machado e Scorzafave (2016) confirmaram diferenças salariais dos professores de acordo com sua formação, a dependência administrativa da instituição, pública ou privada, e ainda em comparação com outros grupos ocupacionais.

Teoricamente, do ponto de vista da distribuição pessoal de renda, as desigualdades salariais podem vir da educação e da experiência, elementos do capital humano, expostos por Mincer (1958), Schultz (1961) e Becker (1975); das condições agradáveis ou não do trabalho, previstas pela teoria dos diferenciais compensatórios (BORJAS, 2012); ou das características pessoais dos trabalhadores, como cor da pele ou gênero, segundo a teoria da discriminação (BECKER, 1971). Podem também ocorrer pela demanda do mercado de trabalho, ou seja, pelo local onde o rendimento foi gerado e pelas estruturas internas, de acordo com a teoria da segmentação (LIMA, 1980).

Tendo em vista a possibilidade da segmentação ocupacional, pelas normas e barreiras institucionais determinadas pela própria carreira do magistério, este artigo procura responder às seguintes indagações: qual é o papel do capital humano nas diferenças salariais que ocorrem na carreira do magistério, das caraterísticas inatas do indivíduo ou das determinações internas ao posto de trabalho em que atua?

O objetivo deste trabalho é analisar os determinantes salariais dos professores com formação superior no Brasil e os impactos que os níveis de ensino nos quais atuam exercem sobre os salários, com base nos microdados da PNAD contínua de 2018.

Este artigo está estruturado em cinco seções, além da Introdução. Na segunda estão resumidas as teorias e evidências sobre o assunto. Na terceira se aplicam a decomposição salarial contrafactual de Oaxaca-Blinder e o procedimento de correção de viés de seleção amostral, e na quarta e na quinta se interpretam os resultados. As conclusões estão na quinta seção. 
2. DIFERENCIAIS DE REMUNERAÇÃO DE PROFESSORES ASSALARIADOS NO BRASIL: CONSIDERAÇÕES TEÓRICAS E EMPÍRICAS

\subsection{Fundamentação teórica das diferenças salariais}

A determinação e as diferenças salariais entre os indivíduos ocorrem por diversos fatores que estão sistematizados nas teorias do diferencial compensatório, do capital humano, da discriminação e da segmentação dos postos de trabalho. Na teoria do diferencial compensatório, inicialmente proposta por Adam Smith, as condições de trabalho causam diferentes impactos na determinação de salários. Segundo Borjas (2012), condições de trabalho adversas se associam a vantagens compensatórias, como remunerações mais altas; já condições agradáveis de trabalho levariam a salários mais baixos.

$\mathrm{Na}$ abordagem do capital humano, Mincer (1958), Schultz (1961) e Becker (1975) defendem que existe uma correlação entre o investimento na formação das pessoas e a distribuição da renda pessoal. O mecanismo mais frequente pelo qual a escolaridade afetaria o rendimento do indivíduo é o aumento da produtividade e da eficiência, provocada pelo desenvolvimento das habilidades cognitivas, o que incrementa o valor de mercado do trabalho.

Educadores e sociólogos, por outro lado, entendem que a atividade educacional é um processo de socialização que providencia informações relevantes sobre o comportamento do indivíduo, mas tanto quanto a teoria convencional do capital humano, essa visão converge para a importância das habilidades e sua condução para o aumento da produtividade. No entanto, há um problema de falta de informações sobre a produtividade dos trabalhadores. Arrow (1973), em alusão à educação superior, expõe tal questão ao considerar que os empregadores têm informações gerais sobre a distribuição estatística das produtividades, mas não conseguem distinguir as produtividades individuais. Nesse sentido, a educação superior seria um dispositivo de triagem, de filtro, que identifica indivíduos de diferentes habilidades educacionais, porém sem garantir as habilidades produtivas.

Outra teoria que explica as diferenças de rendimento é a discriminação econômica no mercado de trabalho, que se dá quando um grupo de indivíduos que têm habilidade, educação, treinamento, experiência e produtividade iguais recebe salários diferentes por causa de características que não implicam em sua produtividade, ou seja, sexo, cor, religião, idioma, condição econômica e social e aparência física (LOUREIRO, 2003). A discriminação no mercado de trabalho pode advir do empregador, do empregado, do cliente e da discriminação estatística.

Na teoria do mercado dual ou teoria da segmentação, conforme Lima (1980) e Corseuil (2002), muito embora não se apresente um corpo teórico homogêneo, a ideia-chave é a de que as diferenças salariais decorrem das características dos postos de trabalho. Segmentos específicos desse mercado têm normas e regras de operação distintas, que determinam o acesso e a remuneração do trabalhador. Algumas são as causas da segmentação. Doeringer e Piore (1970) e Piore (1978) se apoiam no ajuste alocativo como principal determinante da segmentação, pois as firmas estão sempre dispostas a oferecer empregos que exijam diferentes níveis de treinamento e tenham custos distintos associados à turnover, garantindo assim a eficiência por meio de uma equipe diversificada de trabalhadores capazes de atender sua demanda. Explicam que o mercado é dividido em dois segmentos: o primário, que paga os melhores salários, tem mais estabilidade e menor rotatividade, e o secundário, que remunera com os piores salários, é instável e menos atrativo para o trabalhador. 
Em outra visão, Vietorisz e Harrison (1973) procuram explicar a segmentação conforme as diferenças tecnológicas da estrutura industrial. No mercado primário, os investimentos em capital humano acompanham as aplicações em capital físico e tecnológico, gerando aumentos na produtividade e, portanto, nos salários. Já no mercado secundário isso não ocorre, devido à persistência da utilização de técnicas intensivas de mão de obra.

Reich, Gordon e Edwards (1971) afirmam que a origem da segmentação no mercado de trabalho está no esforço consciente dos capitalistas industriais no sentido de dividir e conquistar a força de trabalho. Dessa forma, os capitalistas e o Estado organizariam a produção e as instituições de apoio à produção, ou seja, escolas, sindicatos e outros, mantendo assim o controle sobre o sistema produtivo e reduzindo o poder de barganha salarial dos trabalhadores e seus salários. Nessa abordagem, Lima (1980) resume que as operações institucionais ajudariam a reproduzir a hegemonia capitalista de três maneiras: a) dividindo trabalhadores; b) estabelecendo barreiras à mobilidade entre segmentos; e c) estabelecendo a divisão dos trabalhadores em segmentos. Por fim, na perspectiva da segmentação do mercado de trabalho, as diversas correntes teóricas se complementam para esclarecer as causas das desigualdades salariais que estão associadas às características dos postos de trabalho.

Diante do exposto, o entendimento das desigualdades salariais que existem em um mercado específico para professores, teoricamente, passaria por seus atributos produtivos, suas características inatas não ligadas à produtividade e/ou pelo perfil dos postos de trabalho. As evidências empíricas já existentes sobre o assunto são recuperadas na próxima seção.

\subsection{O mercado docente e os diferenciais de remuneração de professores no Brasil}

O mercado de trabalho docente no Brasil envolve a atuação dos professores em distintos níveis de ensino. O nível básico se refere ao ensino infantil, fundamental e médio, e o ensino superior corresponde à graduação e à pós-graduação (especialização, mestrado, doutorado e pós-doutorado), à extensão e ao ensino sequencial.

Os objetivos dos níveis de ensino estão explícitos na Lei de Diretrizes e Bases da Educação Nacional - Lei n. ${ }^{0}$ 9.394, de 20 de dezembro de 1996 (BRASIL, 1996). Especificamente, o ensino fundamental tem como objetivo desenvolver habilidades como a capacidade de leitura, escrita e cálculo, bem como a compreensão do ambiente natural e social. As finalidades do ensino médio são a preparação básica para o trabalho e a cidadania, com capacidade para se adaptar com flexibilidade às novas condições de ocupação, desenvolvendo a autonomia intelectual. Já o ensino superior tem como objetivos formar diplomados nas diferentes áreas de conhecimento para a inserção em setores profissionais, motivar a pesquisa e a extensão à comunidade, bem como o desenvolvimento, a divulgação e a concretização da ciência, da tecnologia e da cultura. Além disso, deve favorecer o aprimoramento da educação básica pela capacitação de profissionais, pesquisas pedagógicas e aproximação dos dois níveis pelas atividades de extensão universitária.

De forma geral, o ensino básico enfatiza a formação de valores e atitudes, o fortalecimento dos vínculos familiares, da solidariedade e da tolerância, bem como a pessoa humana e a ética. No ensino superior, a ciência e a reflexão, os problemas do mundo e a reciprocidade com a sociedade são fundamentais.

Por outro lado, as carreiras e a remuneração dos professores que atuam nesses diferentes níveis de ensino têm sido recentemente orientadas pelo Plano Nacional de Educação (PNE), instituído pela Lei n. ${ }^{\circ}$ 13.005/2014. Em seus planos subnacionais constam as informações de 
que em 2017 todos os estados federativos já organizavam os Planos de Carreiras e remunerações, com estrutura de acesso e salários, também em cumprimento da Lei n. ${ }^{\circ} 11.738 / 2008$, que estabeleceu o Piso Salarial Profissional Nacional (BRASIL, 2008).

As pesquisas empíricas mostram que o quadro de profissionais da educação básica apresenta uma padronização, ou seja, a maioria é de professoras e de brancos (ALVES; PINTO, 2011). Em relação à formação educacional, cerca de $67,6 \%$ concluíram o ensino superior, sendo que $43 \%$ são graduados, $23,3 \%$ são especialistas e $1,3 \%$ são mestres ou doutores, o que indica que em grande parte há docentes qualificados atuando nesse nível de ensino.

A estrutura remuneratória do professor foi cientificamente analisada sob várias óticas. Em comparação a outros países, constatou-se que os salários dos docentes da educação infantil, do ensino fundamental e do ensino médio no Brasil (2000 a 2011) são inferiores (COSTA; OLIVEIRA, 2011). Dessotti (2011) encontrou que em termos monetários é mais vantajoso para um indivíduo com formação superior trabalhar em ocupações não docentes. Ademais, os professores que atuam no ensino fundamental e estão inseridos no setor privado auferem uma remuneração melhor que os docentes da mesma categoria alocados no ensino público.

Segmentando pelas ocupações no Brasil, o professor com ensino superior que atuava na educação fundamental (antiga $5^{\mathrm{a}}$ a $8^{\mathrm{a}}$ série) recebia parcelas menores do que os economistas, advogados, delegados e, principalmente, médicos e juízes. A desvalorização salarial da ocupação docente impede a atração de profissionais mais qualificados, e os que exercem a profissão enfrentam dilemas ao assumirem uma carga horária de trabalho maior e não desfrutarem de tempo para se dedicar a uma educação continuada e realizar investimentos voltados ao trabalho (SAMPAIO et al., 2002).

Nessa direção, Britto e Waltenberg (2012) encontraram que, especificamente em comparação aos profissionais das ciências e das artes, os professores têm um diferencial de remuneração desfavorável. Em ambas as categorias os profissionais têm dotações semelhantes (escolaridade e experiência), porém, sobre os salários dos docentes essas características têm um peso monetário menor.

Por outro lado, Machado e Scorzafave (2016) investigaram as diferenças salariais entre professores e outras ocupações tipicamente ligadas à carreira docente (Ciências da Educação, Formação de Professores, Língua Materna, Matemática, Biologia e Química). Inferiram que há um diferencial salarial favorável aos docentes, na média e nos quantis 10 e 50 da distribuição salarial, majoritariamente decorrente do componente não explicado na decomposição salarial, ou seja, nas diferenças de estrutura de remuneração.

De forma geral, as pesquisas têm se empenhado no entendimento das desigualdades de salário entre professores e outras ocupações e encontram a relevância de fatores menos relacionados à composição dos grupos do que ao retorno das características, da parcela não explicada nas decomposições salariais.

\section{DADOS E ESTRATÉGIA ECONOMÉTRICA}

\subsection{Base de dados}

O presente estudo utilizou os dados da Pesquisa Nacional de Amostra por Domicílios Contínua (PNAD-C) para o Brasil no ano de 2018. Realizada pelo Instituto Brasileiro de Geografia e Estatística (IBGE), essa pesquisa investiga as características gerais e socioeconômicas da 
sociedade, incluindo educação, trabalho e rendimento. Utilizou-se a primeira das cinco entrevistas realizadas pela PNAD-C pela amplitude da abordagem sobre o mercado de trabalho brasileiro.

A amostra aqui utilizada foi composta de 2,57 milhões de professores ocupados, com formação superior, e que atuam no ensino fundamental, médio ou superior. Foram considerados professores de disciplinas da educação geral do ensino fundamental (do $1 .^{\circ}$ ao $9 .^{\circ}$ ano), do ensino médio e do ensino superior. Os profissionais de ensino com formação de nível superior fazem parte do grupo ocupacional denominado Profissionais das Ciências e Intelectuais (PCI's) ${ }^{4}$.

\subsection{Método para a estimação das equações de salários e para a correção do viés de seleção amostral}

A técnica desenvolvida por Mincer (1974) consiste em mensurar os salários por meio de uma equação log-lin e por Mínimos Quadrados Ordinários (MQO), em que, em sua forma original, os salários são determinados por fatores produtivos (anos de escolarização e experiência). Para este estudo o método de estimação salarial foi ampliado e está representado na Equação 1, a seguir, para os professores ocupados com formação superior completa no Brasil em 2018:

$$
\begin{aligned}
\operatorname{Ln}\left(\mathrm{W}_{\mathrm{h}}\right) & =\beta_{0}+\beta_{1} \mathrm{Es}+\beta_{2} \mathrm{Mes}+\beta_{3} \mathrm{Doc}+\beta_{4} \mathrm{X}+\beta_{5} \mathrm{X}^{2}+\beta_{6} \mathrm{M}+\beta_{7} \mathrm{NB}+\beta_{8} \mathrm{P}+ \\
& +\beta_{9} \text { For }+\beta_{10} \mathrm{UF}_{\mathrm{i}}+\beta_{11} \mathrm{EM}+\beta_{12} \mathrm{UF}_{\mathrm{i}}+\mu_{\mathrm{i}}
\end{aligned}
$$

Considerou-se $\operatorname{Ln}\left(W_{h}\right)$ o salário-hora, Es a especialização, Mes o mestrado e Doc o doutorado, sendo o grupo-base a graduação. A experiência e a experiência ao quadrado foram indicadas por $X \mathrm{e} X^{2}$. A construção da variável experiência foi realizada pela formal tradicional, (idade - anos de estudos - 5) devido às limitações da base de dados. Foram inseridas as variáveis binárias $M$ para o gênero feminino, $N B$ para a cor da pele não branca, $P$ para o setor público e For para a formalidade do emprego. Os amarelos, indígenas e sem declaração foram excluídos da amostra pela baixa representatividade.

Além disso, $E M$ indica os professores que atuam no ensino médio e $E S$ os que atuam no ensino superior (grupo-base: docentes do ensino fundamental). Por fim, usou-se o vetor $U F \mathbf{i}$ para as macroregiões do Brasil (grupo-base: Região Nordeste).

Para corrigir a possibilidade de um viés de seleção amostral, esta pesquisa aplicou o procedimento de Heckman (1979). A técnica de correção inicia-se com o modelo Probit Multinomial, que assume quatro categorias: o Grupo 0 representa os indivíduos não observados; o Grupo 1, os professores do ensino fundamental; o Grupo 2, os do ensino médio; o Grupo 3, os do ensino superior.

A probabilidade de oferta de trabalho dos indivíduos foram condicionadas às suas características, conforme a Equação 2:

$$
\begin{aligned}
\text { PartTrab } & =\beta_{0}+\beta_{1} \text { Es }+\beta_{2} \text { Mes }+\beta_{3} \text { Doc }+\beta_{4} X+\beta_{5} X^{2}+\beta_{6} \mathrm{M}+\beta_{7} \mathrm{NB}+\beta_{8} \mathrm{P}+ \\
& +\beta_{9} \text { For }+\beta_{10} \mathrm{UF}_{\mathrm{i}}+\beta_{11} \mathrm{EM}+\beta_{12} \mathrm{UF}_{\mathrm{i}}+\mu_{\mathrm{i}}
\end{aligned}
$$

\footnotetext{
4 A construção das classes de professores foi realizada com base nos códigos ocupacionais identificados na PNAD-C considerando a variável v4010. Para criar a categoria do ensino fundamental (do $1 .{ }^{\circ}$ ao $9 .^{\circ}$ ano) agregaram-se os códigos ocupacionais 2312 e 2313 . Para criar a classe dos professores do ensino médio utilizou-se o código 2321 e, por último, para os professores do ensino superior adotou-se o código 2340.
} 
Foram consideradas as seguintes características: especialização (Es), mestrado (Mes), doutorado (Doc) - grupo-base: graduados, experiência $(\mathrm{X})$, experiência ao quadrado $\left(\mathrm{X}^{2}\right)$, mulher $(\mathrm{M})$, não branco $(\mathrm{NB})$, chefe de família (CHE), cônjuge (CONJ), filhos (FI) e as macroregiões do Brasil $\left(\mathrm{UF}_{\mathrm{i}}\right)$ - grupo-base: Região Nordeste.

As previsões probabilísticas constituem a etapa seguinte para estimar a Razão Inversa de Mills, cujo coeficiente, se significativo, acarretará em sua inclusão na equação minceriana para a correção do possível viés de seleção amostral.

\subsection{Método para decomposição de diferenciais de salários - Oaxaca-Blinder}

O método da decomposição dos diferenciais de salários é atribuído à Ronald Oaxaca e Alan Blinder e possibilita desagregar a desigualdade salarial advinda das distinções de dotações dos indivíduos (parte explicada) e da parcela não compreendida por esses atributos, proveniente da discriminação ou da segmentação dos postos de trabalho.

Ambos os autores iniciam o procedimento por meio de uma equação minceriana padrão:

$$
\operatorname{Ln}\left(\mathrm{W}_{\mathrm{i}}\right)=\mathrm{Z}_{\mathrm{i}}^{\prime} \beta+\mu_{1} \quad \mathrm{i}=1, \ldots, \mathrm{n}
$$

Nela, $W_{i}$ indica o salário-hora, $Z_{i}^{\prime}$ é o vetor de características individuais, $\beta$ é o vetor de coeficientes e $\mu_{i}$ é o termo de erros.

Oaxaca (1973) expressa as estimações das diferenças salariais por meio da Equação 4:

$$
\operatorname{Ln}(\mathrm{G}+1)=\underbrace{\Delta \mathrm{Z}^{\prime} \beta_{\mathrm{v}}}_{\text {explicada }}+\underbrace{Z_{\mathrm{D}}^{\prime} \Delta \hat{\beta}}_{\text {não explicada }}
$$

O termo $\Delta Z^{\prime} \beta_{\mathrm{V}}$ representa as diferenças explicadas do grupo em vantagem devido às dessemelhanças de dotações observáveis do grupo $\mathrm{V}$ em relação ao grupo $\mathrm{D}$, ou seja, o grupo em vantagem aufere prêmios melhores por ter dotação diferente do grupo em desvantagem. A segunda parte da equação, $\Delta Z^{\prime} \beta_{\mathrm{v}}$, indica (parte não explicada) a diferença dos coeficientes que ocorre pelo fato de as dotações serem valorizadas diferentemente entre os grupos. Essa diferença de ganhos é normalmente associada à discriminação quando comparados grupos étnicos ou de gênero e à segmentação quando comparados grupos ocupacionais, setores econômicos, regiões geográficas e outros.

De outra forma, Blinder (1973) também contribui para esse cálculo com a Equação 5:

$$
\left(\bar{Y}^{H}-\bar{Y}^{L}\right)=\beta_{0}^{H}-\beta_{0}^{L}+\sum_{j} \bar{X}_{j}^{L}\left(\beta_{j}^{H}-\beta_{j}^{L}\right)+\sum_{j} \beta_{j}^{H}\left(\bar{X}_{j}^{H}-\bar{X}_{j}^{L}\right)
$$

Nela, $\sum_{\mathrm{j}} \beta_{\mathrm{j}}^{\mathrm{H}}\left(\overline{\mathrm{X}}_{\mathrm{j}}^{\mathrm{H}}-\overline{\mathrm{X}}_{\mathrm{j}}^{\mathrm{L}}\right)$ indica a parcela das diferenças de rendimento derivada das desigualdades de dotações, semelhante à primeira parte da equação de Oaxaca (1973). De forma análoga, $\sum_{\mathrm{j}} \overline{\mathrm{X}}_{\mathrm{j}}^{\mathrm{L}}\left(\beta_{\mathrm{j}}^{\mathrm{H}}-\beta_{\mathrm{j}}^{\mathrm{L}}\right)$ corresponde à existência de valorações monetárias diferentes para grupos caracterizados semelhantes. $O$ termo $\beta_{0}^{\mathrm{H}}-\beta_{0}^{\mathrm{L}}$ é denominado por Blinder (1973) de "shift-effect", em que as diferenças de rendimentos provém única e exclusivamente de o indivíduo estar inserido em um grupo.

Nesta pesquisa, utilizou-se o método twofold (Equação 5), que consiste em decompor os salários dos professores em duas partes: (1) parte explicada, referente às diferenças de características, tais como aspectos produtivos (pós-graduação Lato Sensu e Stricto Sensu, 
experiência e experiência ${ }^{2}$ ), ser mulher, não branco, estar inserido no setor público, ter emprego formal e residir em determinada macrorregião; (2) parte não explicada, que consiste na segmentação do posto de trabalho dos professores, ou seja, nas diferenças salariais derivadas dos níveis de ensino fundamental, médio e superior.

Esse procedimento incorre no problema de identificação, ou seja, na invariância dos resultados da decomposição frente à escolha arbitrária das variáveis a serem omitidas nos conjuntos de variáveis categóricas utilizadas nas regressões de determinação de salários. Para a correção desse problema, utilizou-se o processo de normalização proposto por Yun $(2005)^{5}$.

\section{DESCRIÇÃO DA AMOSTRA}

As características dos professores com formação superior que ministravam aulas nos níveis de ensino fundamental, médio e superior no Brasil em 2018 estão descritas na Tabela 1. A idade média do docente do ensino fundamental e do ensino médio é de 42 anos, e a do docente de ensino superior é de 45 anos. A experiência média do professor do ensino fundamental e do ensino médio era de 21 anos, e a do docente do ensino superior estava próximo aos 24 anos, ou seja, professores do ensino superior são mais velhos e experientes.

São poucos os docentes com mestrado ou doutorado que atuam nos ensinos fundamental e médio. No ensino superior, $12,47 \%$ dos professores têm apenas ensino superior completo, $12,58 \%$ são especialistas, $25,07 \%$ são mestres e 49,99\% têm doutorado. Os níveis de ensino se diferenciam entre eles na exigência de formação, conforme o artigo 52, parágrafo II, da LDB (BRASIL, 1996), pois as universidades que visam à formação de profissionais de nível superior, de pesquisa, de extensão e de domínio e cultivo do saber humano precisam, pelo menos, ter um terço do corpo docente com titulação acadêmica de mestrado ou doutorado.

Como se pode observar nos dados da Tabela 1, a mulher predomina no mercado de trabalho docente, mas perde espaço conforme os níveis de ensino se alteram. Uma possível justificativa seria que em nível de ensino mais alto a professora precisa de mais tempo e dedicação para a formação educacional e preparação de suas aulas, devido à complexidade de conhecimento. Dessa forma, a mulher se dedicaria menos à sua família e mais à sua formação.

Rabelo e Martins (2010) ressaltam que a sociedade associa a profissão docente às características femininas, por isso existem mais mulheres do que homens nessa carreira, principalmente no ensino fundamental, pois as famílias podem ter preconceito em relação a homens para cuidar de seus filhos. As escolas, portanto, parecem preferir contratar mulheres. Os cursos de Pedagogia e Letras estão entre os dez com o maior número de vagas ofertadas do Brasil, sendo que a maioria dos inscritos nesses cursos é do sexo feminino, de acordo com Gatti (2010).

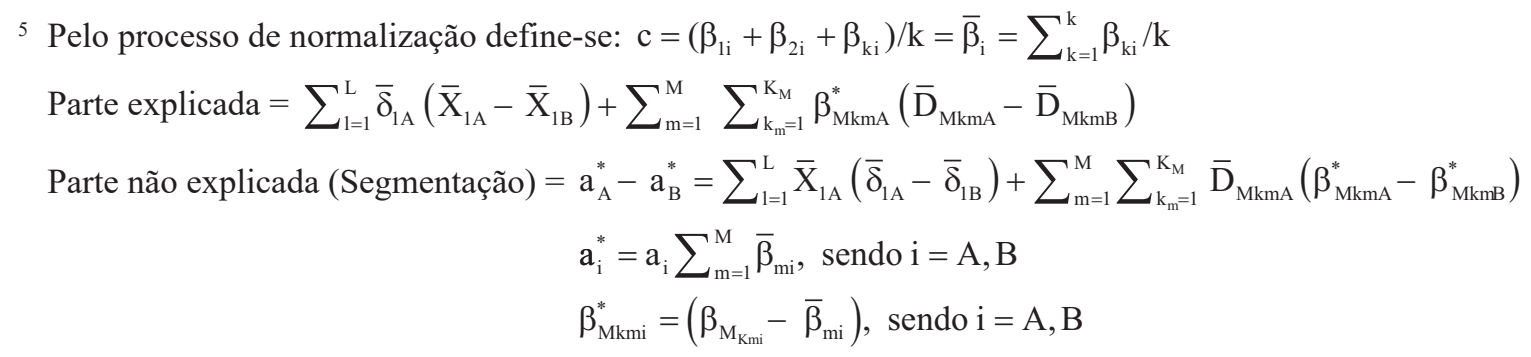

Em que: $\mathrm{L}$ corresponde às variáveis contínuas $(\mathrm{X}), \mathrm{M}$ à quantidade de grupos de dummies, $\mathrm{K}_{\mathrm{mi}}$ às categorias de cada grupo das dummies $(\mathrm{K}-1)$ em que uma delas foi omitida, $\mathrm{Y}_{\mathrm{i}}-\mathrm{Ln}\left(\mathrm{W}_{\mathrm{h}}\right)$ ao logaritmo do salário-hora, e $\mathrm{i}=\mathrm{A}$ ou B (níveis de ensino). Além disso, $D_{K_{m i}}=$ Dummy e $K_{m i}$ são as dummies do modelo. Inicia-se em $K_{m i}=2$ devido à omissão da categoria 1 para evitar multicolinearidade perfeita. O erro aleatório é representador por $e_{i}$. 
TABELA 1 - PERFIL DOS PROFESSORES ASSALARIADOS, COM ENSINO SUPERIOR, QUE ATUAM NOS DIFERENTES NÍVEIS DE ENSINO NO BRASIL (2018)

\begin{tabular}{lrrrrrr}
\hline \multicolumn{1}{c}{ Variáveis } & \multicolumn{2}{c}{ Ensino Fundamental } & \multicolumn{2}{c}{ Ensino Médio } & \multicolumn{2}{c}{ Ensino Superior } \\
\hline Idade (média) & 42,25 & $(10,14)$ & 42,39 & $(10,60)$ & 45,24 & $(11,88)$ \\
\hline Experiência (média) & 21,64 & $(10,05)$ & 21,55 & $(10,56)$ & 24,26 & $(11,88)$ \\
\hline Graduação (\%) & 58,52 & $(0,49)$ & 58,33 & $(0,42)$ & 12,47 & $(0,14)$ \\
\hline Especialização (\%) & 38,38 & $(0,46)$ & 31,73 & $(0,40)$ & 12,58 & $(0,18)$ \\
\hline Mestrado (\%) & 2,72 & $(0,37)$ & 8,29 & $(0,27)$ & 25,07 & $(0,36)$ \\
\hline Doutorado (\%) & 0,37 & $(0,16)$ & 1,64 & $(0,24)$ & 49,99 & $(0,87)$ \\
\hline Homem (\%) & 14,97 & $(0,43)$ & 36,84 & $(0,46)$ & 49,32 & $(0,38)$ \\
\hline Mulher (\%) & 85,03 & $(0,49)$ & 63,16 & $(0,36)$ & 50,68 & $(0,27)$ \\
\hline Branco (\%) & 47,53 & $(0,46)$ & 53,40 & $(0,39)$ & 71,16 & $(031)$ \\
\hline Não Branco (\%) & 52,47 & $(0,49)$ & 46,60 & $(0,39)$ & 28,84 & $(0,22)$ \\
\hline Chefe de família (\%) & 45,21 & $(0,48)$ & 49,37 & $(0,41)$ & 53,03 & $(0,30)$ \\
\hline Público (\%) & 81,65 & $(0,50)$ & 77,78 & $(0,41)$ & 53,09 & $(0,25)$ \\
\hline Privado (\%) & 18,35 & $(0,39)$ & 22,22 & $(0,32)$ & 46,91 & $(0,31)$ \\
\hline Formal (\%) & 94,37 & $(0,48)$ & 95,99 & $(0,40)$ & 94,52 & $(0,28)$ \\
\hline Informal (\%) & 5,63 & $(0,38)$ & 4,01 & $(0,25)$ & 5,48 & $(0,19)$ \\
\hline Salário mensal R\$ (média) & $2.571,95$ & $(1.715,34)$ & $3.305,15$ & $(2.121,49)$ & $7.331,61$ & $(5.345,37)$ \\
\hline Horas trabalho/semana (média) & 33,91 & $(11,65)$ & 38,13 & $(12,05)$ & 38,09 & $(14,32)$ \\
\hline Salário hora R\$ (média) & 18,77 & $(12,80)$ & 21,25 & $(14,03)$ & 46,96 & $(35,22)$ \\
\hline Total (\%) & 100 & - & 100 & - & 100 & - \\
\hline Total de professores (milhões) & 1,48 & & 0,75 & & 0,34 & \\
\hline Fon & & & & & \\
\hline
\end{tabular}

Fonte: Elaboração própria, com base nos dados da PNAD-C de 2018.

Nota: Os valores entre parênteses correspondem ao desvio padrão.

Dos profissionais de ensino do nível fundamental, 47,53\% são brancos e $52,47 \%$ são não brancos. Dos professores do nível médio, $53,40 \%$ são brancos e $46,60 \%$ são não brancos. Já no ensino superior $71,16 \%$ deles são brancos e $28,84 \%$ são não brancos. No entanto, existe um agravante: tal qual ocorre com as mulheres, conforme o nível de ensino se eleva, o trabalhador não branco perde espaço no mercado docente. Essa desigualdade entre brancos e não brancos pode se dar pela dificuldade de inserção à educação que a população negra teve historicamente. Passos e Laffin (2012) apontam que muitos jovens e adultos negros procuram a Educação de Jovens e Adultos (EJA) para terminar a educação básica por conta dessa desvantagem educacional acumulada.

Em relação à posição na família, professores que atuam no ensino superior são, na maioria, chefes de família, contrariamente aos que trabalham no ensino básico. Em relação a isso existe uma grande discrepância entre o setor público e privado no ensino fundamental $(81,65 \%$ e $18,35 \%)$ e no ensino médio $(77,78 \%$ e $22,22 \%)$. No ensino superior, $53,09 \%$ dos professores trabalham em instituições da rede pública e, 46,91\% em instituições da rede privada. 
Há de se lembrar, nesse ponto, do aumento da participação do setor privado no ensino superior após os anos 1990, respaldado pela Constituição de 1988, pela Lei de Diretrizes e Bases (LDB) de 1996 e pelas mudanças nas estruturas normativas do Ministério da Educação em 1997, que contribuíram para o aumento de oferta de cursos superiores nas redes privadas do Brasil (SAMPAIO, 2011).

\section{TABELA 2 - SALÁRIO-HORA MÉDIO (R\$) DOS PROFESSORES ASSALARIADOS, COM ENSINO SUPERIOR, QUE ATUAM NOS DIFERENTES NÍVEIS DE ENSINO NO BRASIL (2018)}

\begin{tabular}{lcccccc}
\hline Variáveis & \multicolumn{2}{c}{ Ensino fundamental } & \multicolumn{2}{c}{ Ensino médio } & \multicolumn{2}{c}{ Ensino superior } \\
\hline Formal & 19,07 & $(12,76)$ & 21,37 & $(13,91)$ & 48,30 & $(35,67)$ \\
Informal & 13,76 & $(12,33)$ & 18,31 & $(16,63)$ & 23,82 & $(11,54)$ \\
\hline Público & 19,32 & $(11,97)$ & 21,35 & $(14,01)$ & 53,67 & $(33,96)$ \\
Privado & 16,32 & $(15,73)$ & 20,90 & $(14,14)$ & 39,36 & $(35,13)$ \\
\hline Homem & 19,43 & $(14,46)$ & 22,68 & $(16,08)$ & 51,38 & $(41,10)$ \\
Mulher & 18,66 & $(12,48)$ & 20,41 & $(12,63)$ & 42,65 & $(27,74)$ \\
\hline Branco & 20,27 & $(13,69)$ & 21,35 & $(14,19)$ & 50,46 & $(37,88)$ \\
Não branco & 17,45 & $(11,79)$ & 21,01 & $(13,77)$ & 38,14 & $(26,91)$ \\
\hline Apenas graduação & 18,57 & $(12,70)$ & 19,91 & $(11,31)$ & 33,91 & $(27,31)$ \\
Especialização & 20,85 & $(13,06)$ & 22,67 & $(15,16)$ & 32,96 & $(19,83)$ \\
Mestrado & 26,05 & $(15,91)$ & 27,59 & $(18,09)$ & 35,99 & $(21,51)$ \\
Doutorado & 25,46 & $(14,03)$ & 42,95 & $(35,11)$ & 63,39 & $(41,99)$ \\
\hline Média geral & 18,77 & $(12,80)$ & 21,25 & $(14,03)$ & 46,96 & $(35,22)$ \\
\hline
\end{tabular}

Fonte: Elaboração própria, com base nos dados da PNAD-C de 2018.

Nota: Os valores entre parênteses correspondem ao desvio padrão.

Os professores que atuam no ensino fundamental têm um salário médio mensal de $\mathrm{R} \$ 2.571,95$, os do ensino médio recebem $\mathrm{R} \$ 3.305,15 \mathrm{e}$, por último, os do ensino superior ganham em média R \$7.331,61. Os docentes do ensino fundamental trabalham aproximadamente 34 horas e os do ensino médio e superior trabalham 38 horas semanais, recebendo em média um salário-hora de $\mathrm{R} \$ 18,77, \mathrm{R} \$ 21,25$ e $\mathrm{R} \$ 46,96$, respectivamente.

Percebe-se na Tabela 2 que a formalização é alta para todos os níveis, e o salário-hora dos professores inseridos no setor formal é maior do que no informal, especialmente para os docentes universitários. Os dados revelam ainda que as instituições públicas de ensino pagam um salário-hora maior para os docentes do que as particulares, e a diferença é mais intensa no ensino superior. A menor diferença salarial público privada acontece no ensino médio.

As características do ensino público e privado no Brasil são distintas tanto na relação professor/aluno quanto na atuação de ensino. Na escola particular, o aluno exerce a função de cliente, portanto, a postura do docente nessas instituições deve assegurar a qualidade e o desempenho do aluno. Já nas escolas públicas há precarização no trabalho docente devido à falta de estrutura, de material e ao aumento da carga horária de trabalho (NAIFF et al., 2010).

Muitos trabalhos comprovam que em termos salariais o homem sobressai perante a mulher, tanto em relação aos setores quanto às ocupações em que estão inseridos. Nesta 
pesquisa, percebeu-se que a mulher é proporcionalmente mais concentrada na carreira docente do que o homem (Tabela 1), mas sua remuneração é menor do que o dos professores em todos os níveis de ensino. Apesar da abertura de mercado para a mulher na área docente, o fator gênero ainda impacta no salário.

Outra característica particular dos docentes e de seus salários é referente à cor da pele. O professor não branco que atua no ensino fundamental recebe $86,09 \%$ da remuneração do profissional branco; no ensino superior essa diferença é ainda maior, com 75,58\%. No entanto, a média salarial dos professores do ensino médio, tanto para os brancos $(\mathrm{R} \$ 21,35)$ quanto para os não brancos (R $\$ 21,01)$, é similar.

Por fim, a titulação dos docentes altera seus salários. A conclusão de cursos de especialização e mestrado favorece a remuneração dos professores do ensino fundamental; todos os níveis de pós-graduação são positivos aos docentes do ensino médio, e o mestrado e o doutorado são mais importantes em termos de retornos salariais para os docentes do ensino superior.

\section{SALÁRIOS DOS PROFESSORES E SEGMENTAÇÃO DOS POSTOS DE TRABALHO NO BRASIL: RESULTADOS E INTERPRETAÇÕES DA PESQUISA}

\subsection{Determinação de salários dos professores do ensino fundamental, médio e superior no Brasil}

Os fatores que influenciam a remuneração dos docentes estão elencados na Tabela 3. A interpretação para as variáveis contínuas, como a experiência, é a de que cada unidade acrescentada de ano de experiência promoverá uma alteração percentual no salário. Para os elementos categóricos (gênero, cor e outras), a variação percentual acontece caso o indivíduo pertença a algum grupo, por exemplo, ser mulher ou ser não branco ${ }^{6}$.

Ressalta-se que nesta pesquisa todos os docentes têm formação de nível superior e o aumento da titulação contribui positivamente para melhorias salariais de forma crescente. Os professores especialistas ganham $9,54 \%$, os mestres, $32,91 \%$, e os doutores, $95,42 \%$ a mais do que os graduados. Desagregando por níveis de ensino, o retorno do mestrado é maior para os docentes que atuam no ensino fundamental, enquanto para os do ensino médio e superior o mestrado e doutorado fazem a diferença salarial.

Os dados da Tabela 3 indicam também que o aumento de uma unidade de experiência acarreta ao salário do professor brasileiro um aumento de $1,76 \%$. No caso do docente de ensino fundamental, eleva em 1,95\% sua remuneração, e no de ensino médio, em 1,50\%. As constatações confirmam a Teoria do Capital Humano, sendo que cada acréscimo de uma unidade nos aspectos produtivos (educação e experiência) sinaliza uma produtividade maior do indivíduo e este irá auferir uma renda maior.

Para todas as categorias de ensino, ser professora reduziria o salário em 10,48\% nos rendimentos salariais em relação aos professores, ainda que do total dos docentes das três categorias, em média, 85,03\% são do sexo feminino (Tabela 1). Além disso, ser não branco reduz o salário em 9,89\%. Essa penalização é maior para níveis de atuação mais elevados de ensino.

\footnotetext{
${ }^{6}$ O procedimento de Heckman foi realizado, mas não houve a necessidade de correção do viés de seleção amostral.
} 
Do ponto de vista institucional, os professores que atuam em escolas ou faculdades públicas são mais valorizados monetariamente $(13,55 \%)$ do que os que trabalham nas instituições privadas. A formalidade do trabalho também tem influência positiva no salário, gerando um acréscimo de $15,03 \%$ na remuneração dos docentes. A remuneração dos docentes também se altera conforme sua região de residência, sendo que morar no Distrito Federal implica um aumento salarial de 65,99\% em relação aos professores residentes na Região Nordeste.

\section{TABELA 3 - EQUAÇÕES SALARIAIS PARA OS PROFESSORES DO ENSINO FUNDAMENTAL, MÉDIO E SUPERIOR NO BRASIL (2018)}

\begin{tabular}{|c|c|c|c|c|}
\hline Variáveis & Geral & $\begin{array}{c}\text { Ensino } \\
\text { Fundamental }\end{array}$ & Ensino Médio & Superior \\
\hline \multirow{2}{*}{ Especial } & $0,0954^{*}$ & $0,0813^{*}$ & 0,0662 & 0,1096 \\
\hline & $(0,0210)$ & $(0,0297)$ & $(0,0477)$ & $(0,1742)$ \\
\hline \multirow{2}{*}{ Mestrado } & $0,3291 *$ & $0,3016^{*}$ & $0,2955^{*}$ & 0,1604 \\
\hline & $(0,0473)$ & $(0,0883)$ & $(0,0688)$ & $(0,1340)$ \\
\hline \multirow{2}{*}{ Doutorado } & $0,9542 *$ & 0,2279 & $0,7576^{*}$ & $0,8242 *$ \\
\hline & $(0,0687)$ & $(0,1692)$ & $(0,1823)$ & $(0,1334)$ \\
\hline \multirow{2}{*}{ Experiência } & $0,0176^{*}$ & $0,0195^{*}$ & $0,0150^{* *}$ & 0,0138 \\
\hline & $(0,0036)$ & $(0,0064)$ & $(0,0071)$ & $(0,0117)$ \\
\hline \multirow{2}{*}{ Experiência $^{2}$} & $-0,0001$ & $-0,0002$ & $-0,0001$ & $-0,0001$ \\
\hline & $(0,0001)$ & $(0,0001)$ & $(0,0002)$ & $(0,0002)$ \\
\hline \multirow{2}{*}{ Mulher } & $-0,1048^{*}$ & $-0,0482$ & $-0,0630$ & $-0,0649$ \\
\hline & $(0,0293)$ & $(0,0616)$ & $(0,0418)$ & $(0,0673)$ \\
\hline \multirow{2}{*}{ Não-Branco } & $-0,0989^{*}$ & $-0,0742 * *$ & 0,0124 & $-0,1756^{* *}$ \\
\hline & $(0,0204)$ & $(0,0328)$ & $(0,0415)$ & $(0,0852)$ \\
\hline \multirow{2}{*}{ Público } & $0,1355^{*}$ & $0,1857^{*}$ & $-0,0597$ & $0,3337 *$ \\
\hline & $(0,0248)$ & $(0,0480)$ & $(0,0541)$ & $(0,0882)$ \\
\hline \multirow{2}{*}{ Formal } & $0,1503^{*}$ & 0,0724 & 0,1517 & $0,3904 * *$ \\
\hline & $(0,0506)$ & $(0,1049)$ & $(0,1196)$ & $(0,1523)$ \\
\hline \multirow{2}{*}{ Centro-Oeste } & $0,1878^{*}$ & $0,1669^{*}$ & $0,2229 * *$ & 0,0832 \\
\hline & $(0,0322)$ & $(0,0462)$ & $(0,0805)$ & $(0,1496)$ \\
\hline \multirow{2}{*}{ Norte } & $0,0920^{*}$ & $0,0815^{* *}$ & $0,2539^{*}$ & $-0,0356$ \\
\hline & $(0,0265)$ & $(0,0367)$ & $(0,0600)$ & $(0,1099)$ \\
\hline \multirow{2}{*}{ Sudeste } & $0,1177^{*}$ & $0,1492 *$ & 0,0725 & $-0,0210$ \\
\hline & $(0,0241)$ & $(0,0384)$ & $(0,0520)$ & $(0,0906)$ \\
\hline \multirow{2}{*}{ Sul } & $0,1616^{*}$ & $0,1746^{*}$ & $0,1708^{*}$ & 0,1278 \\
\hline & $(0,0273)$ & $(0,0402)$ & $(0,0591)$ & $(0,1041)$ \\
\hline \multirow{2}{*}{ Distrito-Federal } & $0,6599^{*}$ & $0,6909^{*}$ & $0,8677^{*}$ & 0,1067 \\
\hline & $(0,0460)$ & $(0,0640)$ & $(0,0697)$ & $(0,2192)$ \\
\hline
\end{tabular}




\begin{tabular}{|c|c|c|c|c|}
\hline Variáveis & Geral & $\begin{array}{c}\text { Ensino } \\
\text { Fundamental }\end{array}$ & Ensino Médio & Superior \\
\hline \multirow{2}{*}{ Ensino Médio } & $0,0429 * * *$ & \multirow{2}{*}{-} & \multirow{2}{*}{-} & \multirow{2}{*}{-} \\
\hline & $(0,0244)$ & & & \\
\hline \multirow{2}{*}{ Ensino Superior } & $0,4887 *$ & \multirow{2}{*}{-} & \multirow{2}{*}{-} & \multirow{2}{*}{-} \\
\hline & $(0,0566)$ & & & \\
\hline \multirow{2}{*}{ Constante } & $8,7460 *$ & $8,2105^{*}$ & $10,2186^{*}$ & $12,7980 *$ \\
\hline & $(0,0619)$ & $(0,1180)$ & $(0,1548)$ & $(0,2031)$ \\
\hline Observações & 5,995 & 2,523 & 1,215 & 484 \\
\hline$R$-squared & 0,2892 & 0,1281 & 0,1367 & 0,3204 \\
\hline
\end{tabular}

Fonte: Elaboração própria, com base nos dados da PNAD-C de 2018.

Nota: 1. Para minimizar o problema de heterocedasticidade, utilizou-se o procedimento de erros robusto. 2. Os valores correspondem ao antilogaritmos dos coeficientes: $\left(e^{\beta}-1\right)$. 3. $(*)$ significância até 5\%; (sem asterisco) não significante.

De modo geral, as equações mincerianas mostram que a titulação de especialização, mestrado ou doutorado eleva os salários dos professores, mas de forma diferenciada entre os níveis de atuação. Os resultados também indicam uma possível segmentação dos postos de trabalho docente, visto que nos três níveis de ensino se remunera diferentemente o profissional, com base em características individuais similares.

\subsection{Decomposição das fontes das diferenças salariais}

Os resultados apresentados nesta seção se referem à decomposição salarial dos professores assalariados do Brasil em 2018 que exerciam suas atividades nos níveis fundamental, médio e superior. A decomposição de Oaxaca-Blinder consiste em dividir as diferenças salariais dos indivíduos em duas partes. A parte explicada atribui o impacto percentual no salário do docente (setor em desvantagem), caso o docente tivesse as mesmas características selecionadas no presente estudo dos indivíduos atuantes no setor em vantagem. A parte não explicada está relacionada às diferenças salariais dos professores associados aos diferentes níveis em que eles atuam (efeito segmentação por nível de ensino - proxy da segmentação).

As informações contidas na Tabela 4 relacionam as diferenças salariais entre os professores do ensino fundamental e do ensino médio. Da diferença total de salários, $41,66 \%$ refere-se à parte explicada pelas dotações dos docentes e 58,23\% pode ser explicada pelo efeito nível de ensino, ou seja, pela segmentação do posto de trabalho.

\section{TABELA 4 - DECOMPOSIÇÃO DE OAXACA-BLINDER PARA DIFERENÇA DE RENDIMENTOS SALARIAIS DOS PROFESSORES ASSALARIADOS QUE ATUAM NO ENSINO FUNDAMENTAL E MÉDIO NO BRASIL (2018)}

\begin{tabular}{lcc}
\hline \multicolumn{1}{c}{ Grupo } & Coeficientes & $\begin{array}{c}\text { Coeficientes na forma } \\
\text { exponencial }\end{array}$ \\
\hline Ensino Fundamental & $2,83^{*}$ & $16,92^{*}$ \\
\hline Ensino Médio & $2,92^{*}$ & $18,53^{*}$ \\
\hline
\end{tabular}




\begin{tabular}{llll}
\hline \multicolumn{1}{c}{ Diferenças } & Coeficientes & $\begin{array}{c}\text { Participação } \\
\text { relativa (\%) }\end{array}$ & $\begin{array}{c}\text { Impacto percentual } \\
\text { no salário }\end{array}$ \\
\hline Explicada & $0,0377^{*}$ & $\mathbf{4 1 , 6 6}$ & $\mathbf{3 , 8 4 *}$ \\
\hline Aspectos produtivos & $0,0150^{* * *}$ & 39,79 & $1,52^{* * *}$ \\
\hline Mulher & 0,0144 & 38,20 & 1,45 \\
\hline Não-Branco & $-0,0006$ & $-1,59$ & $-0,06$ \\
\hline Setor Público & 0,0027 & 7,16 & 0,27 \\
\hline Formal & 0,0002 & 0,53 & 0,02 \\
\hline Macrorregião & 0,006 & 15,92 & 0,6 \\
\hline Efeito nível de ensino & $0,0527^{* *}$ & $\mathbf{5 8 , 2 3}$ & $\mathbf{5 , 4 2 * *}$ \\
\hline Diferença total & $0,0905^{*}$ & $\mathbf{1 0 0}$ & $\mathbf{9 , 4 7 *}$ \\
\hline
\end{tabular}

Fonte: Elaboração própria, com base nos dados da PNAD-C de 2018.

Nota: 1. Para minimizar o problema de heterocedasticidade, comum em modelos de determinação de salários, utilizou-se o procedimento de erros robusto de White (1980). 2. (*) significância até 5\%; (sem asterisco) não significante. 3. Grupo em desvantagem: ensino fundamental.

De outra forma, os professores que atuam no ensino fundamental (setor em desvantagem) deveriam obter um acréscimo de 9,47\% nos salários para equipará-los aos dos docentes do ensino médio. Caso os professores do ensino fundamental tivessem as mesmas características selecionadas dos docentes do ensino médio, seus ordenados iriam aumentar em 3,84\%. E na ausência da segmentação dos postos de trabalho, os salários dos professores do ensino fundamental deveriam aumentar em $5,42 \%$, sendo que essa diferença se dá pelo nível de ensino em que eles atuam.

As diferenças salariais dos professores do ensino fundamental e do ensino superior estão representadas na Tabela 5. Dessa diferença total, 61,97\% refere-se ao efeito nível de ensino. O papel das outras características estudadas é bem menor, ou seja, apenas 38,03\% das diferenças salariais entre os docentes do ensino fundamental e médio são esclarecidas pelos outros elementos referentes à experiência e à conclusão do mestrado e doutorado.

TABELA 5 - DECOMPOSIÇÃO DE OAXACA-BLINDER PARA DIFERENÇA DE RENDIMENTOS SALARIAIS DOS PROFESSORES ASSALARIADOS QUE ATUAM NO ENSINO FUNDAMENTAL E SUPERIOR NO BRASIL (2018)

\begin{tabular}{|c|c|c|c|}
\hline Grupo & \multicolumn{2}{|c|}{ Coeficientes } & $\begin{array}{c}\text { Coeficientes na forma } \\
\text { exponencial }\end{array}$ \\
\hline Ensino Fundamental & \multicolumn{2}{|c|}{2,83} & 16,92 \\
\hline Ensino Superior & \multicolumn{2}{|c|}{3,66} & 38,84 \\
\hline Diferenças & Coeficientes & $\begin{array}{l}\text { Participação } \\
\text { relativa }(\%)\end{array}$ & $\begin{array}{c}\text { Impacto percentual no } \\
\text { salário }\end{array}$ \\
\hline Explicada & $0,3160 *$ & 38,03 & $37,16 *$ \\
\hline Aspectos produtivos & $0,3266^{*}$ & 103,48 & $38,62 *$ \\
\hline Mulher & 0,0255 & 8,07 & 2,58 \\
\hline Não-Branco & $0,0441 * *$ & 13,96 & $4,51 * *$ \\
\hline
\end{tabular}




\begin{tabular}{lccc}
\hline \multicolumn{1}{c}{ Diferenças } & Coeficientes & $\begin{array}{c}\text { Participação } \\
\text { relativa (\%) }\end{array}$ & $\begin{array}{c}\text { Impacto percentual no } \\
\text { salário }\end{array}$ \\
\hline Setor Privado & $-0,0812^{*}$ & $-25,70$ & $-7,80^{*}$ \\
\hline Formal & $-0,0036$ & $-1,15$ & $-0,36$ \\
\hline Macrorregião & 0,0046 & 1,44 & 0,46 \\
\hline Efeito nível de ensino & $0,5150^{*}$ & $\mathbf{6 1 , 9 7}$ & $\mathbf{6 7 , 3 6 *}$ \\
\hline Diferença total & $0,8309^{*}$ & $\mathbf{1 0 0}$ & $\mathbf{1 2 9 , 5 4 *}$ \\
\hline
\end{tabular}

Fonte: Elaboração própria, com base nos dados da PNAD-C de 2018.

Nota: 1. Para minimizar o problema de heterocedasticidade, comum em modelos de determinação de salários, utilizou-se o procedimento de erros robusto de White (1980). 2. (*) significância 5\%; (sem asterisco) não significante. 3. Grupo em desvantagem: ensino fundamental.

Na perspectiva dos impactos salariais, os dados da Tabela 5 indicam que para os salários dos professores do ensino fundamental se equipararem aos dos docentes do ensino superior, seus rendimentos deveriam ter um acréscimo de 129,54\%. Caso os professores do ensino fundamental tivessem as mesmas características observadas nos docentes do ensino superior, seus salários deveriam sofrer um impacto positivo de 37,16\%. Dessa relação se destacam os aspectos produtivos, apesar de serem insuficientes para explicar as diferenças salariais entre os professores. Além disso, se os dois segmentos de ensino remunerassem da mesma forma, os salários dos docentes do ensino fundamental deveriam aumentar em 67,36\%.

A decomposição salarial dos professores do ensino médio e superior está exposta na Tabela 6. Da diferença salarial total dos docentes, 39,92\% pode ser explicada pelas variáveis indicadas e $60,08 \%$ pela segmentação dos postos de trabalho.

Para os salários dos professores do ensino médio se igualarem aos dos docentes do ensino superior, eles deveriam receber um incremento de $109,69 \%$. Se os professores do ensino médio tivessem os mesmos atributos produtivos e não produtivos dos docentes do ensino superior, sua remuneração deveria impactar em 34,39\%. O efeito nível de ensino acontece devido à segmentação do posto de trabalho do professor; na ausência desse efeito, o salário do docente do ensino médio deveria aumentar em 56,03\%.

\section{TABELA 6 - DECOMPOSIÇÃO DE OAXACA-BLINDER PARA DIFERENÇA DE RENDIMENTOS SALARIAIS DOS PROFESSORES ASSALARIADOS QUE ATUAM NO ENSINO MÉDIO E SUPERIOR NO BRASIL (2018)}

\begin{tabular}{lccc}
\hline \multicolumn{1}{c}{ Grupo } & Coeficientes & $\begin{array}{c}\text { Coeficientes na forma } \\
\text { exponencial }\end{array}$ \\
\hline Ensino Médio & $2,92^{*}$ & 18,53 \\
\hline Ensino Superior & $3,66^{*}$ & 38,84 \\
\hline \multicolumn{1}{c}{ Diferenças } & Coeficientes & $\begin{array}{c}\text { Participação } \\
\text { relativa (\%) }\end{array}$ & $\begin{array}{c}\text { Impacto percentual no } \\
\text { salário }\end{array}$ \\
\hline Explicada & $0,2956^{*}$ & $\mathbf{3 9 , 9 2}$ & $\mathbf{3 4 , 3 9 *}$ \\
\hline Aspectos produtivos & $0,3200^{*}$ & 108,27 & $37,72^{*}$ \\
\hline Mulher & 0,0107 & 3,61 & 1,07 \\
\hline
\end{tabular}




\begin{tabular}{lccc}
\hline \multicolumn{1}{c}{ Diferenças } & Coeficientes & $\begin{array}{c}\text { Participação } \\
\text { relativa (\%) }\end{array}$ & $\begin{array}{c}\text { Impacto percentual no } \\
\text { salário }\end{array}$ \\
\hline Não-Branco & $0,0341^{* *}$ & 11,52 & $3,46^{* *}$ \\
\hline Setor Público & $-0,0684^{*}$ & $-23,15$ & $-6,62^{*}$ \\
\hline Formal & $-0,0041$ & $-1,39$ & $-0,41$ \\
\hline Macrorregião & 0,0034 & 1,14 & 0,34 \\
\hline Efeito nível de ensino & $0,4449^{*}$ & $\mathbf{6 0 , 0 8}$ & $\mathbf{5 6 , 0 3 *}$ \\
\hline Diferença total & $0,7405^{*}$ & $\mathbf{1 0 0}$ & $\mathbf{1 0 9 , 6 9 *}$ \\
\hline
\end{tabular}

Fonte: Elaboração própria, com base nos dados da PNAD-C de 2018.

Nota: 1. Para minimizar o problema de heterocedasticidade, comum em modelos de determinação de salários, utilizou-se o procedimento de erros robusto de White (1980). 2. (*) significância até 5\%; (sem asterisco) não significante. 3. Grupo em desvantagem: ensino médio.

Na Tabela 7 está uma síntese da decomposição dos salários dos docentes referente aos grupos estudados no Brasil. Ela revela que os segmentos de ensino não remuneram o professor da mesma forma, mesmo se tivessem características similares observadas no presente estudo. Isso ocorre devido às peculiaridades dos postos de trabalho na carreira docente, aos planos de carreira e à remuneração próprios de cada nível de atuação. Esse efeito do nível de ensino de atuação do professor é maior quando comparado com o ensino superior, principalmente entre a categoria superior $\mathrm{x}$ fundamental. Os resultados obtidos vão ao encontro da Teoria da Segmentação, visto que a educação, por si só, não foi suficiente para explicar as diferenças de rendimentos entre os níveis de ensino.

TABELA 7 - SÍNTESE DA DECOMPOSIÇÃO SALARIAL PARA A DIFERENÇA DE RENDIMENTOS SALARIAIS DOS PROFESSORES ASSALARIADOS NO BRASIL (\%) (2018)

\begin{tabular}{lcccccc}
\hline \multirow{2}{*}{ Grupo } & \multicolumn{2}{c}{ Diferença total } & \multicolumn{2}{c}{ Explicada } & \multicolumn{2}{c}{ Efeito nível de ensino } \\
\cline { 2 - 7 } & \multicolumn{2}{c}{$\left(\overline{\mathbf{Y}}^{\mathrm{H}}-\overline{\mathbf{Y}}^{\mathbf{L}}\right)$} & $\sum_{\mathbf{j}} \beta_{\mathrm{j}}^{\mathrm{H}}\left(\overline{\mathbf{X}}_{\mathbf{j}}^{\mathrm{H}}-\overline{\mathbf{X}}_{\mathbf{j}}^{\mathbf{L}}\right)$ & $\beta_{0}^{\mathbf{H}}-\beta_{0}^{\mathrm{L}}+\sum_{\mathbf{j}} \overline{\mathbf{X}}_{\mathbf{j}}^{\mathbf{L}}\left(\beta_{\mathbf{j}}^{\mathbf{H}}-\beta_{\mathbf{j}}^{\mathrm{L}}\right)$ \\
\cline { 2 - 7 } & Part. (\%) & Impacto & Part. (\%) & Impacto & Part. (\%) & Impacto \\
\hline Méd. x Fund. & 100 & $9,47^{*}$ & 41,66 & $3,84^{*}$ & 58,23 & $5,42^{* *}$ \\
\hline Sup. x Fund. & 100 & $129,54^{*}$ & 38,03 & $37,16^{*}$ & 61,97 & $67,36^{*}$ \\
\hline Méd. x Sup. & 100 & $109,69^{*}$ & 39,92 & $34,39^{*}$ & 60,08 & $56,03^{*}$ \\
\hline
\end{tabular}

Fonte: Elaboração própria, com base nos dados da PNAD-C de 2018.

Nota: 1. Fund. (Ensino Fundamental); Méd. (Ensino Médio); Sup. (Ensino Superior) e Part. (Participação Relativa). 2. (*) significância até 5\%; (sem asterisco) não significante.

\section{CONCLUSÃO}

O presente trabalho buscou analisar as fontes das diferenças salariais dos professores com formação superior entre os níveis fundamental, médio e superior no Brasil, em 2018. De modo geral, o perfil dos docentes assalariados com ensino superior que atuam nos diferentes níveis de ensino no Brasil mostrou que seus salários aumentam conforme se eleva o nível de atuação profissional, a idade média e a experiência. 
Na carreira docente brasileira, o não branco perde espaço para o branco conforme se eleva o nível de ensino em que lecionam, devido à falta de qualificação ou à discriminação de cor da pele. Isso mostra a importância das políticas públicas, como os programas de incentivo de educação do negro, principalmente as cotas para negros nas universidades. Confirmou-se também que a mulher predomina no mercado de trabalho docente, porém também perde espaço para o homem conforme os níveis de ensino avançam. Uma explicação para isso pode ser o fato de a mulher ter de decidir entre retardar sua maternidade ou se preparar mais em termos de educação e profissionalmente para os conteúdos complexos exigidos no ensino superior.

Com base no estudo dos fatores que determinam os salários, destacou-se a importância de se cursar uma pós-graduação, isto é, especialização, mestrado ou doutorado, e das experiências adquiridas pelos professores. Além disso, concluiu-se que o fato de ser homem no mercado docente proporciona ordenados maiores que o das mulheres, da mesma forma que ser branco acarreta remuneração maior do que ser não branco. Também se percebeu que as instituições públicas pagam melhor o docente do que a rede privada, exceto para a categoria ensino médio. Professores que atuam no ensino médio e superior são melhor remunerados comparados aos do ensino fundamental.

A decomposição salarial dos docentes com formação superior permitiu identificar que as dotações dos professores são importantes para explicar as diferenças salariais em distintos níveis de atuação, mas são insuficientes. A estrutura da carreira e a remuneração para cada nível de atuação docente é capaz de gerar diferenças salariais relevantes e mais pronunciadas não associadas às características dos docentes.

Essas constatações podem auxiliar as instituições educacionais e a política pública na avaliação dos salários dos professores porque explicitam os fatores que contribuem para a determinação e os hiatos dos rendimentos desses profissionais no Brasil.

\section{REFERÊNCIAS}

ALVES, Thiago; PINTO, José Marcelino de Rezende. Remuneração e características do trabalho docente no Brasil: um aporte. Cadernos de Pesquisa, São Paulo, v. 41, n. 143, p. 606-639, maio/ago. 2011.

ARROW, Kenneth J. Higher education as a filter. Journal of Public Economics, Amsterdã, n. 2, p. 193-216, 1973.

BARBOSA, Andreza. Os salários dos professores brasileiros: implicações para o trabalho docente. 2011. 208 f. Tese (Doutorado em Educação Escolar) - Faculdade de Ciências e Letras, Universidade Estadual Paulista, Araraquara, 2011.

BECKER, Gary. S. Human capital: a theoretical and empirical analysis, with special reference to education. 2. ed. New York: Columbia University Press, 1975.

. S. The economics of discrimination. Chicago: University of Chicago Press, 1971.

BLINDER, Alan. S. Wage discrimination: reduced form and structural estimates. The Journal of Human Resources, Wisconsin, v. 8, n. 4. out. 1973.

BORJAS. George. Economia do trabalho. 5. ed. Porto Alegre: AMGH, 2012.

BRASIL. Lei n. ${ }^{\circ}$ 9.394, de 20 de dezembro de 2008. Estabelece as diretrizes e bases da educação nacional. Brasília, DF, 1996. 
. Lei n. ${ }^{\circ} 11.738$, de 16 de julho de 2008. Regulamenta a alínea "e" do inciso III do caput do art. 60 do Ato das Disposições Constitucionais Transitórias, para instituir o piso salarial profissional nacional para os profissionais do magistério público da educação básica. Diário Oficial da União, Brasília, DF, 2008.

. Ministério da Educação, Brasília, DF, 2015. Disponível em: http://portal.mec.gov.br/. Acesso em: 5 jun. 2019.

BRITTO, Ariana Martins de.; WALTENBERG, Fábio. D. É atrativo tornar-se professor do Ensino Médio no Brasil? Evidências com base em decomposições paramétricas e não paramétricas. Estudos Econômicos, São Paulo, v. 44, n. 1, p. 5-44, mar. 2012.

CORSEUIL, Carlos Henrique. (org.). Estrutura salarial: aspectos conceituais e novos resultados para o Brasil. Rio de Janeiro: Ipea, 2002.

COSTA, Gilvan Luiz Machado; OLIVEIRA, Dalila Andrade. Trabalho docente no ensino médio no Brasil. Revista Perspectiva, Florianópolis, v. 29, n. 2, 727-750, jul./dez. 2011.

DESSOTTI, M. V. Os determinantes da escolha da ocupação docente: uma análise do diferencial de salário do mercado de professores do ensino fundamental. 2011. 65 f. Dissertação (Pós-graduação em Ciências Econômicas) - Universidade de São Paulo, São Paulo, 2011.

DOERINGER, Peter B.; PIORE, Michael. J. Equal employment opportunity in Boston. Industrial Relations: a journal of economy and society, v. 9, n. 3, p. 324-339, 1970.

GATTI, Bernadete. A formação de professores no Brasil: características e problemas. Educação e Sociedade, Campinas, v. 31, n. 113, p. 1.355-1.379, dez. 2010.

HECKMAN, James. J. Sample selection bias as a specification error (with an application to the estimation of labour supply functions). Econometrica, v. 47, mar. 1979.

IBGE - INSTITUTO BRASILEIRO DE GEOGRAFIA E ESTATÍSTICA. Pesquisa Nacional por Amostra de Domicílio Contínua (PNAD-C), 2018. Rio de Janeiro: IBGE. Disponível em: http://www. ibge.gov.br. Acesso em: 15 jun. 2019.

INEP - Instituto Nacional de Estudos e Pesquisas Educacionais Anísio Teixeira. Plano Nacional de Educação 2014-2024. Brasília, DF, 2015.

INEP - Instituto Nacional de Estudos e Pesquisas Educacionais Anísio Teixeira. Relatório de Monitoramento do $\mathbf{1}^{\mathbf{0}}$ ciclo das Metas do Plano Nacional de Educação: biênio 2014-2016. Brasília, DF, 2016.

LIMA, Ricardo. Mercado de trabalho: o capital humano e a teoria da segmentação. Pesquisa e Planejamento Econômico, v. 1, n. 10, p. 217-272, 1980.

LOUREIRO, Paulo R. A. Uma resenha teórica e empírica sobre economia da discriminação. Revista Brasileira Econômica, Rio de Janeiro, v. 57, n. 1, p. 125-157, mar. 2003.

MACHADO, Laura Mueller; SCORZAFAVE, Luiz Guilherme Dácar da Silva. Distribuição de salários de professores e outras ocupações: uma análise para graduados em carreiras tipicamente ligadas à docência. Revista Brasileira de Economia, Rio de Janeiro, v. 70, n. 2, p. 203-220, jun. 2016.

MINCER, Jacob. Family investments in human capital: earnings of Women. National Bureau of Economic Research, p. 76-110, 1974. 
. Investment in human capital and personal income distribution. Journal of Political Economy, v. 66, n. 4, p. 281-302, 1958.

NAIFF, Luciene Alves Miguez et al. Ensino público e privado: comparando representações sociais de professores sobre suas habilidades. Revista Psicologia e Pesquisa, Juiz de Fora, v. 4, n. 1, p. 57-64, 2010.

OAXACA, Ronald. Male-Female wage differentials in urban labor markets. International Economic Review, v. 14, n. 3, out. 1973.

PASSOS, Joana Célia dos. As desigualdades educacionais, a população negra e a educação de jovens e adultos. In: LAFFIN, Maria Hermínia Lage Fernandes. (Org.). Educação de Jovens e Adultos, diversidade(s) e o mundo do trabalho, v. 1, p. 103-162, 2012.

PIORE, Michael. J. Dualism in the labor market: a response to uncertainty and flux. The case of France. Revue économique, v. 29, n.1, p. 26-48, 1978.

RABELO, Amanda Oliveira; MARTINS, António Maria. A mulher no magistério brasileiro: um histórico sobre a feminização do Magistério. In: CONGRESSO LUSO-BRASILEIRO DE HISTÓRIA DA EDUCAÇÃO, 4., 2010, Uberlândia. Anais [...] Aveiro: FCT, 2010. p. 6.167-6.176.

REICH, Michael; GORDON, David M.; EDWARDS, Richard C. A theory of labor market segmentation. The American Economic Review, v. 63, n. 2, p. 359-365, 1973.

SAMPAIO, Carlos E. M. et. al. Estatísticas dos professores no Brasil. Revista Brasileira e Pedagoga, Brasília, v. 83, n. 203/204/205, p. 85-120, jan./dez. 2002.

SAMPAIO, Helena. O setor privado de ensino superior no Brasil: continuidades e transformações. Revista Ensino Superior, Campinas, n. 4, p. 28-43, out. 2011.

SCHULTZ, Theodore. W. Investment in human capital. American Economic Review, Nashville, v. 51, n. 1, p. 1-17, mar. 1961.

SOUZA, Maria Cristina Cacciamali de. Mercado de trabalho: abordagens duais. Revista de Administração de Empresas, Rio de Janeiro, v. 18, n. 1, p. 59-69, jan./mar. 1978.

VIETORISZ, Thomas; HARRISON, Bennet. Labor market segmentation: positive feedback and divergent development. The American Economic Review, Nashville, v. 63, n. 2, p. 366-376, 1973.

YUN, M. A simple solution to the identification problem in detailed wage decompositions. Economic inquiry, v. 43, n. 4, p. 766-772, 2005.

Recebido em: 02/01/2020

Aceito para publicação em: 12/05/2020 